Heinrich Garibert he wrote two small volumes of verse. As has been said of him by an Italian colleague, "Under the cloak of a biologist he preserved the spirit of a poet."

He was born at Königsberg in 1863, and there he died in October last. He was Assistant to Miehelson, and on the latter's death in 1891 he became Director of the University Polyclinic and Professor later on.

He was a great worker and writer, and both his works and his writings were of good quality. He particularly studied scleroma, lupus, syphilis and leprosy. I have had occasion to quote his excellent researches on the complications of frontal sinusitis. He also published two beautiful atlases, which are well worthy of a place in every library.

\title{
B. Baginsky.
}

(Born May 24, 1848. Died November 24, 1919.)

Dr. Baginsky was the doyen of Liber-dozents of oto-laryngology in Berlin. He first practised as a general physician in one of the most populous quarters, and it was only in 1880 that he interested himself particularly in oto-laryngology. He wrote little, but taught well, and was much esteemed by all who became closely acquainted with him.

STC. T.

\section{REVIEWS.}

The Medical Annual: A Year-Book of Treatment and Practitioner's Index for 1920. (Thirty-eighth year.) Pp. 639. Bristol : John Wright \& Sons, Ltd. London : Simpkin, Marshall, Hamilton, Kent \& Co., Ltd.

The "Medical Annual" is ever fresh and as interesting as it is instructive. It is, if possible, more stuffed with good things than usual. Our specialty is dealt with by Dr. Watson-Williams, of Clifton, and Dr. Fraser, of Edinburgh. 'The former gives much information in regard to the nose and throat. Among other practical points he describes the treatment of ozæna by applications of glycerine and liquid glucose with approbation. The abstracts of articles on acromegaly of the larynx, associated paralyses of the larynx, cancer, tuberculosis, and war neuroses of the larynx are of special interest.

Dr. Fraser's abstracts are, as usual, most complete, and their value is considerably enhanced by his crisp and judicial comments. The vestibular tests formulated by Jones are described in detail, as also Ernest Sachs's note of warning regarding the reliability of the results claimed for the examination of the vestibular apparatus and Dench's reminder as to the variations coming within the normal standard.

French writes in praise of the vaccine treatment of hay-fever. Under the heading of X-ray diagnosis, cardiospasm is said to be an exceedingly common affection. Reference is made for full information on this condition to Hill's paper on "Dilatation of the Esophagus without Anatomical Stenosis," and the discussion on it in the Section of Laryngology of the Royal Society of Medicine.

Other branches of medicine and surgery are reported on in such an attractive way that the specialist is led to regret that his scope is not the wider one of the general practitioner, with whom, according to Sir 